\title{
A Subjective Approach of the Performance of Edvard Grieg's Piano Concerto in A minor, Op. 16
}

\author{
CRISTINA RĂDUCANU, Lecturer, PhD \\ "George Enescu" National University of Arts Iași \\ ROMANIA*
}

\begin{abstract}
Starting from a stylistic analysis based on musical language elements, this study offers a personal standpoint with respect to the interpretation and performance of Edvard Grieg's Piano Concerto in A minor, op. 16. The author accounts for all the technical and interpretive observations starting from a structural analysis of the opus. The reflections on various melodic, harmonic, rhythmic, dynamic or agogic characteristics come to reinforce the rationale for the subjective choices of how to perform this piece. The article is not by far an exhaustive study on the topic; it merely offers a personal viewpoint and understanding of this Concerto based on several musical excerpts that have been deemed particularly relevant by the author, who is a pianist as well as a piano teacher. Given that the literature on the stylistic and performative analysis of major piano repertoire is sadly scarce, the author wishes to provide pianists and researchers alike with a paper that may serve them in their artistic or academic enquiries. As this Concerto is very well-known and enthusiastically approached by most pianists due to its beautiful, impressive themes and brilliant virtuosic passages, the author has considered it opportune to present her own point of view as a performing pianist for other pianists who may be strictly interested in various versions to resolve technical-performative issues or, perhaps, who may wish to merely contemplate this opus from a different angle.
\end{abstract}

Keywords: Grieg, Concerto, piano performance, technique, interpretive, movement.

\section{Introduction}

Edvard Grieg's Piano Concerto in A minor is one of the best-known Romantic works of its kind. This is mainly due to its particularly Norwegian melos and the brilliant piano writing characteristic of the fast passages. Grieg is a master of the miniature and his compositional skills excel in shorter works, such as vocal and instrumental miniatures. Nevertheless, his Piano Concerto op. 16 is, and will probably forever be, one of the best-liked and most often performed piano pieces of the genre.

"The concerto had been premiered in Copenhagen (1869) by Norwegian pianist Edmund Neupert; performances in Leipzig (1872), Brussels (1874), London (1874), and New York (1874) soon followed.” (Kijas, 2013, p. 42)

* cristinaandra.raducanu@gmail.com 
Its New York performance is followed by a review in one of the journals of the time: "The Grieg concerto is quite new and seems to be full of beautiful and original ideas. It is long indeed since anything so fresh and charming in the way of pianoforte composition has been presented here." (Kijas, 2013, p. 42)

The Concerto contains all the elements specific to Grieg's piano writing: the lyrical character, the folkloric nature of certain themes, the rhythm pertaining to Norwegian dances and songs, the tonal harmony specific to Romanticism as well as the modal harmony borrowed from musical folklore, all brought together by a particular musical writing with original elements that altogether render a unique, unmistakable style.

Even though Grieg's works contain folkloric quotations, the composer writes mostly in the style of traditional music. Pablo Casals said that "Grieg's music is not only rooted in Norwegian folklore, but it expresses the soul, the tradition and the specificity of an entire nation." (Corredor, 1964, p. 149)

The melodic expression exhibiting a traditional Norwegian character is a typical feature of Grieg's piano pieces. His melodies are simple yet welldefined. The composer makes frequent use of tonal or modal pentatonic structures, while his themes are particularly expressive and easy to remember. "His power of portraying a scene or a mood, a landscape or a state of mind, and of surrounding a simple musical statement with an aura of enchantment are exemplified again and again in his works." (Dale, 1943, p. 195)

Among the features of his writing, we note the descending thirds, the transition from major to minor tonalities and vice-versa, the ample use of ornamentation (for instance, double appoggiaturas), the repetition of short yet expressive motifs in ascending or descending sequences at third intervals, the use of augmented fourths.

As concerns rhythm, the composer draws yet again on traditional Norwegian music, resorting not only to songs but also to dances. His works frequently display various rhythmic features pertaining to traditional dances such as the Springar, the Halling or the Gangar.

"The rhythm of traditional Norwegian dances exhibits structural characteristics entirely specific to choreographic genres: strange accents; the moving of these accents within the rhythmic pattern, which gives the pattern a whimsical character; lively dynamic contrasts along the entire dance; various combinations between the rhythm of the melody and the dance steps which are typical of Norwegian choreography, all together producing an interesting, vivacious rhythm." (Dolinescu, 1964, p. 139)

In his works, the composer makes use of the tonal harmony, specific to Romanticism, as well as the modal, typical of traditional songs. The originality of his harmonic style, however, resides in the way he positions himself with respect to the harmonic peculiarities of the traditional song. 
"His delving into the world of the traditional song reveals new facets of the modal world, the tone and the particular expression given by the nontraditional successions (strings of parallel fifths used in the accompaniment, figurative resolutions of the leading-note, successive sevenths and ninths deduced from the modal or pentatonic structure, the use of chromaticism as a colourful element and not as a means to change the tonal centre), creating an individual, unique and original language." (Iliuţ, 1996, p. 387)

The composer employs a very wide dynamic range, from subtle whispers to rich sonorities. He relies on the consistent use of both the damper pedal, which supports bravuras on the entire keyboard, and the soft pedal as a means to colourfully refine a more discreet sound.

Grieg's piano works are strewn with unique ornamentation. Filigree passages and musical embroideries give his music a particular character which sets him aside in the context of European Romanticism.

His use of forms does not go beyond the traditional, as the composer is not an innovator in this respect. However, as the Romantic nature and the Norwegian ethos fuse in pre-existing forms, the effect of his compositions is all the newer and more original.

\section{From structure to interpretation to performance}

Conceived in the sonata form, the first movement of the Concerto lacks a separate exposition by the orchestra, to the difference of other concertos composed by the Viennese classics. Following a single measure performed by the timpani in a stormy crescendo, the piano opens in a spectacular manner, playing an introductive section of five bars in chords, octaves and arpeggios. This is a rather difficult passage with respect to both technical and expressive aspects; the pianist must be prepared physically as well as emotionally in order to be able to perform such a great virtuosic passage immediately after coming on stage, which makes the Concerto all the more difficult. A good pianist will surely capture the audience from the start with this emblematic opening.

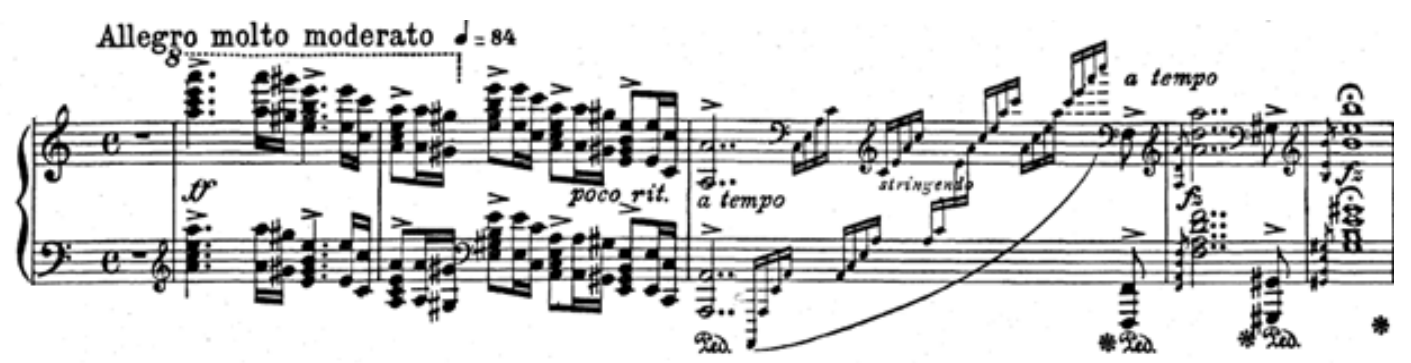

Fig. 1 E. Grieg, Piano Concerto in A minor, $1^{\text {st }}$ mvt, mm. 1-6 
The first theme is introduced by the clarinet. Then the piano brings up the main thematic group which consists in the two contrasting thematic elements: the rhythmic and the melodic-expressive. The former opens in A minor and is reprised in $\mathrm{C}$ major; it has a chord structure, a punctuated rhythm with accents on the weak beats.

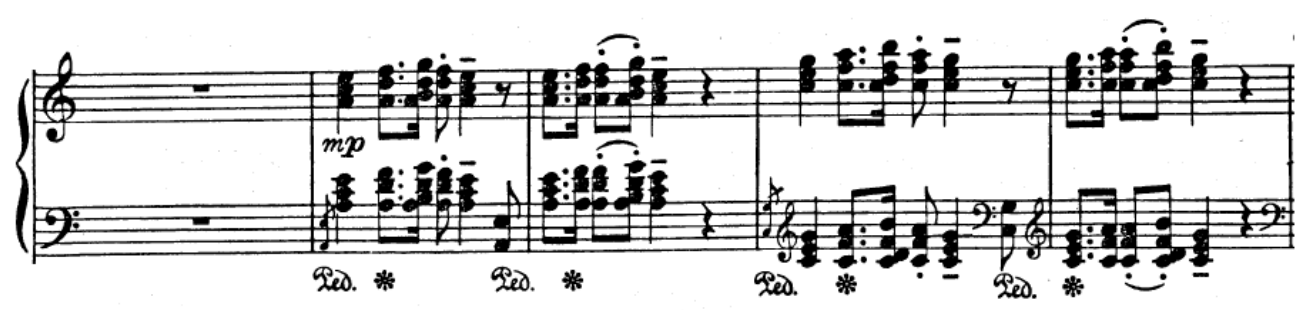

Fig. 2 E. Grieg, Piano Concerto in A minor, $1^{\text {st }}$ mvt, mm. 18-22

In order to be able to render accurately the lively character required by the composer's chosen writing technique, the pianist must observe faithfully the key attack indicated in the score; it is therefore essential to distinguish between staccato, tenuto and the final portamento by using an appropriate touch.

The pianist's focus should be on rendering the dynamics as colourfully as possible. I believe the first and second measures of the first thematic exposition (A minor) should be differentiated from one another based on the echo principle $(m p-p)$. Moreover, the same criterion should apply to the reprise in the relative major, this time beginning in stronger dynamics $(m f)$ so as to highlight the importance of reiterating the musical idea.

The latter thematic element ( $\mathrm{E}$ major) is characterised by a melodic structure containing ascending augmented fourths. Since the intervals provide this theme with a Norwegian air, it is necessary that they be emphasized by an expressive tension. The technical difficulty lies in bringing out the main melodic line from the arpeggiated accompaniment in quintoles and sextolets divided between both hands. Thus, the right hand must tackle two sonorous layers that ought to be clearly differentiated one from the other from a dynamic point of view. The highlight of the main melodic line can be acquired by letting the weight of the arm on the fingers 3,4 and 5 , while the accompaniment is played in softer dynamics, the fingers barely touching the keys.

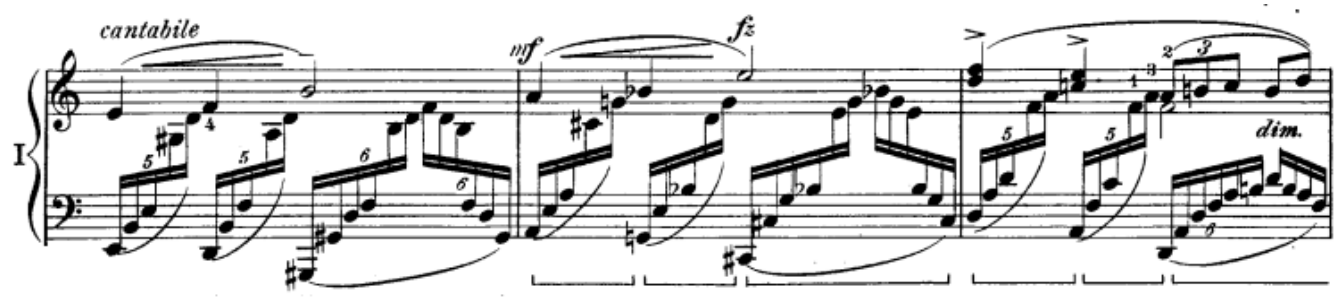




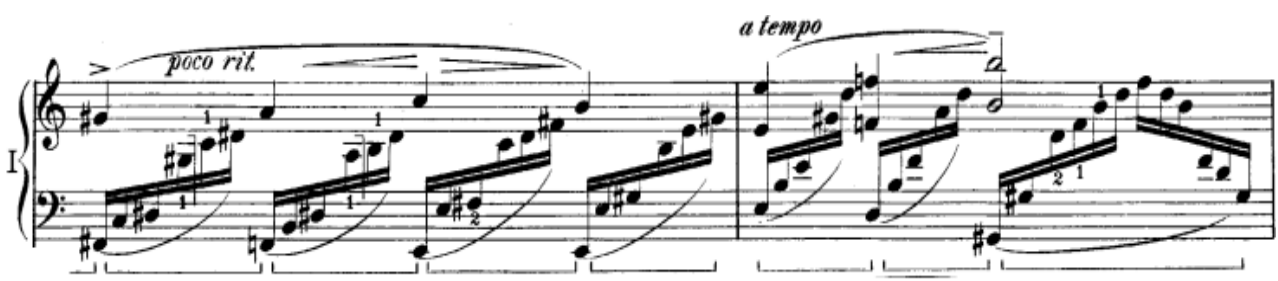

Fig. 3 E. Grieg, Piano Concerto in A minor, $1^{\text {st }}$ mvt, mm. 23-27

The section animato e molto leggiero represents the bridge to the second theme. Here, the melody is played by the right hand in the upper register, in a playful, dance-like manner. The left-hand accompaniment in quavers accentuates this impression due to the accents on the weak beats $(2$ and 4$)$. The appoggiaturas and punctuated rhythm of upper register make this section more colourful. From a technical point of view, the focus should be on playing the double notes clearly and simultaneously and highlighting the upper melodic line by creating two distinct sound planes.

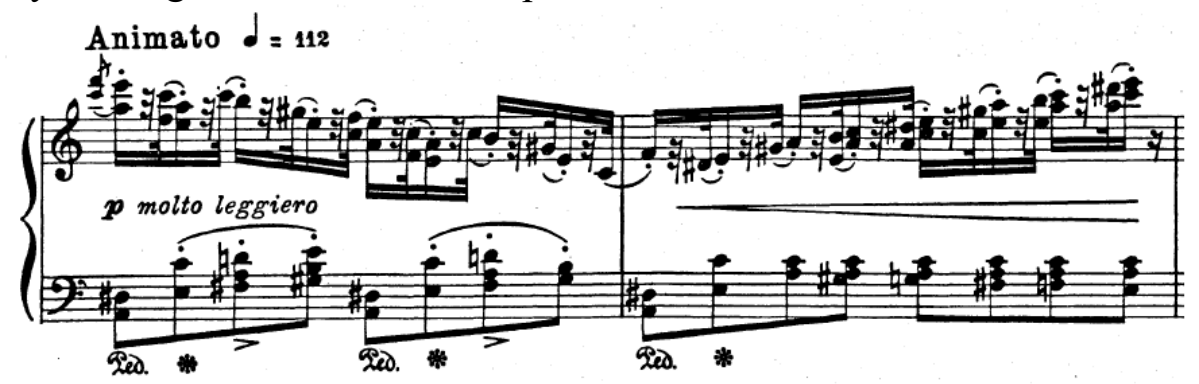

Fig. 4 E. Grieg, Piano Concerto in A minor, $1^{\text {st }}$ mvt, mm. 31-32

This fragment suggests the Norwegian dance called the Halling, which is characterized by a binary rhythm and a lively nature. "It is enchanting due to the freshness of the intonations and the rhythmic ingenuity. Its highly expressive features consist of: strong dynamic contrasts which create an increasingly whimsical rhythmic pattern resulting from inserting several calm steps in the middle of the fiery dance; strange accents which are moved within the rhythm; interpolated simple triple time and compound duple time $(3 / 8$ and $6 / 8$, respectively). All these reveal the artistry of the dance and express a wide array of emotions, of good mood with frequent humorous manifestations, of sheer vivacity expressed by a rhythm with dynamic degrees matching musicality." (Dolinescu, 1964, pp. 139-140)

The character of this Norwegian dance can be rendered, in the first place, by selecting the appropriate tempo. It is also recommended that the brilliant technique in a fast tempo be corroborated by the observance of the accents as directed in the score. Similar accents on weak beats are found in bars 43-47, on the $4^{\text {th }}$ beat. 
The second theme is firstly played in $\mathrm{C}$ major by the cello, the direction being piu lento. Four measures later, it is taken up by the piano, in the same tonality but with several additional ornamental additions. The sinuous melody in the right hand exudes tranquility and revery. The legato can be performed by maintaining a supple wrist and attacking the keys at keyboard level without articulation. The structure of the musical phrase in the form of question and answer gives the pianist the opportunity to create very rich and impressive images by using extremely contrasting dynamics. The polyrhythm created by the two sound planes (melody and accompaniment) amplifies the feeling of peacefulness and the lyrical character of the theme, rendering it more profound and expressive.

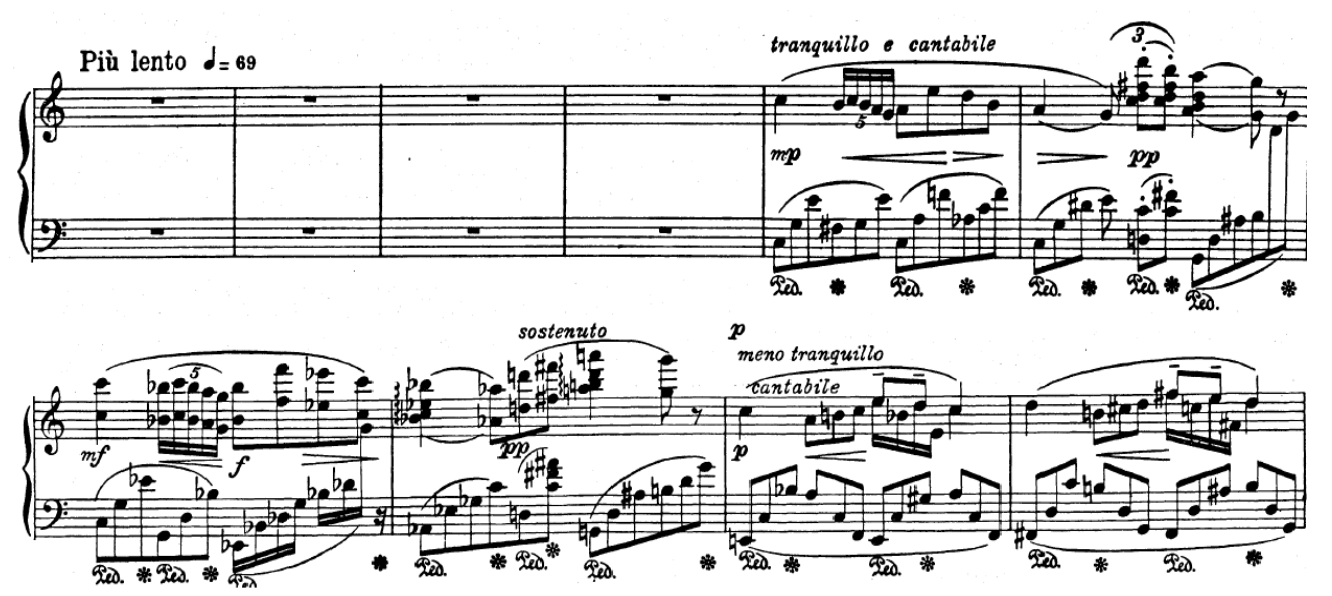

Fig. 5 E. Grieg, Piano Concerto in A minor, $1^{\text {st }}$ mvt, mm. 49-58

This splendid theme is an excellent proof of Grieg's melodic talent due to its beauty and sublimeness. The warm sound of the descant, the vertical structure of the polyrhythm taking into account the relationship between the two sonorous planes, and the tranquillity that must be given to the musical discourse - these are issues that a good pianist will have to identify and tackle minutely.

The transition towards the development is achieved by extending the secondary theme with a passage in chords and octaves that acquires great expressiveness by emphasizing the chordal extremes (the bass and the soprano). It generates an accumulating tension due to a constant amplification from a dynamic (crescendo molto) as well as an agogic point of view (piu vivo, stretto). The pianist should commit affectively to this passage which is impressive with respect to the multitude of conveyed emotions culminating with a chord in $s f f$.

The development opens in $\mathrm{C}$ major with the rhythmic motif in the introduction performed by the orchestra in $f f$ and is reprised later in D minor. 
The tempo instruction is animato, followed by a contrasting section in tranquillo, initially in $\mathrm{E}$ minor (minor dominant). The orchestra plays the first idea of the main theme (the flute) in $\mathrm{E}$ minor and then in $\mathrm{F}$ minor. The piano plays a secondary role, performing an arpeggiated passage in sextolets and septolets. The semiquavers should be played in $p$, dolce, as equally as possible, highlighting the notes on beats 1 and 3 which make up a gradual, step-by-step descent that coincides with the one played by the orchestra.

The section tranquillo culminates with a virtuosic bravura written in demisemiquavers and taking up the entire keyboard, with the composer's directions being brilliante and fff. Therefore, it is recommended that this passage be played with both hands, alternatively, to ensure an easier and, at the same time, more brilliant performance. In this instance, the pianist should follow the homogeneity of the musical discourse by transitioning fluently from one hand to the other.

The bravura is followed by an adaptation of the musical material from the second idea of the main thematic group in A major and B major. This passage is like a play upon echoes, Grieg's dynamic indications being $f$ and $p$ (tre corde and una corda). Then the tension amplifies, the dynamics become stronger and stronger, the tempo is rapidly increasing (stretto), leading to the climax of the development in bars 110113. A few bars before, in 108, the indication is fff, but I believe it is preferable to begin in softer dynamics in order to be able to amplify it up to the climax, thus ensuring a more spectacular overall effect. In the same bar, 108, the F note on beats 1 and 3 as well as the last two notes of the measure ( $\mathrm{F}$ and $\mathrm{E}$ ) should be emphasized. The latter two should be played separately, not all together as a passage.

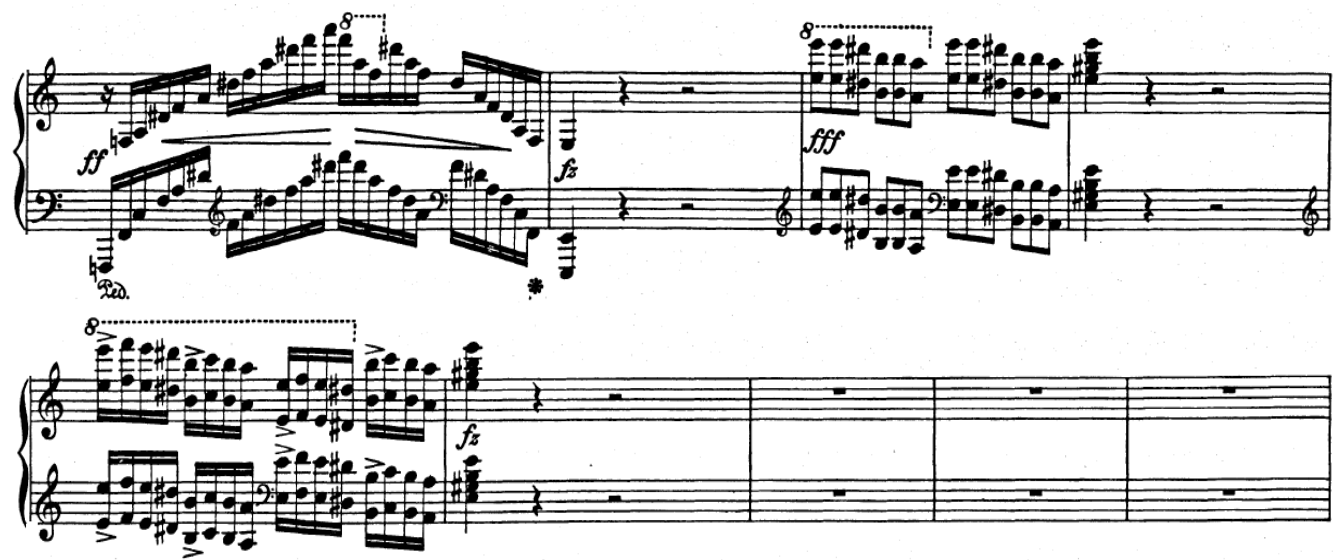

Fig. 6 E. Grieg, Piano Concerto in A minor, $1^{\text {st }}$ mvt, mm. 108-116

Starting with bar 110, the piano performs in fff a rhythmic adaptation in octaves, in E minor, of the motif in the introduction, first in triolets and then in semiquavers. Towards the end of the development, the atmosphere becomes 
more peaceful, with the brass (horn and trombone) playing the rhythmic motif of the first theme in a continuous diminuendo.

The octaves should be played less technically and more expressively, yet without taking too much agogic liberty. In bar 112, keeping the rubato for the octaves in semiquavers seems the correct choice, given the composer's indication to highlight the first semiquaver of each beat. Thus, the performance achieves great effect.

The reprise opens with the piano playing the main thematic group. The composer forgoes the introduction of the solo instrument in the exposition, as well as the theme played initially by the orchestra. It is quite interesting to note that Grieg suggests $p$ instead of $m p$ for the debut of the first theme. That is why the reprise should not be viewed as an emphasis on that musical idea, but rather as a reminiscence.

The aspects that differ from the exposition are mainly at the level of harmony and orchestration. For example, in the main thematic group, the second theme is not reprised by the piano in octaves with orchestral accompaniment, but it is played by the orchestra only.

In the reprise, the secondary theme appears in the tonality of its parallel key, A major. The composer goes from major to minor and vice-versa with great ease, a characteristic feature of his writing which frequently occurs in the Concerto.

The cadence opens with an arpeggio on the subdominant chord (D minor) with $\mathrm{F}$ (the third) in the bass, a chord which is picked up by the piano from the end of the reprise.

After the first fragment in adagio comes a section in presto, and the last three sequences before going back to the initial tempo should be performed increasingly slowly. The first is indicated as meno presto, the second - più moderato, and the third - andante, ending with the very slow lento, the composer even adding molto ritenuto under the last few notes. We shouldn't overlook the half rest before the in tempo section, whose role is to enhance the tension created anyway by the diminished tempo.

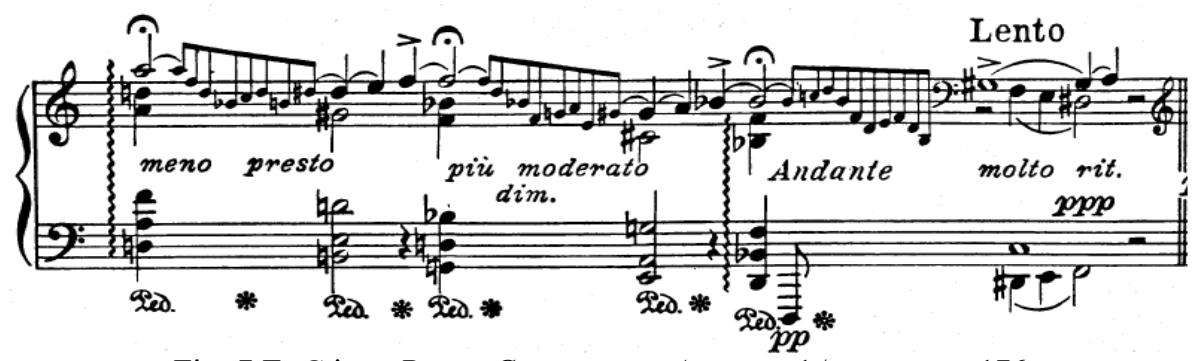

Fig. 7 E. Grieg, Piano Concerto in A minor, $1^{\text {st }}$ mvt, mm. 176 
Starting from bar 177 (in tempo), the pianist should focus on highlighting the melody at the right hand. This melody is a variation of the first musical idea in the main thematic group, this time written in octaves. The inner trill voice can hinder the performance, that is why the pianist needs to practise it to perfection in order to be able to play it easily in piano without going over the melodic line of the descant. The passage is all the more difficult as the composer envisages a melodic line legato sempre, which means that the octaves have to be maintained on the keyboard until the last moment, while the fingers 2 and 3 play the trill of the inner voice.

A study option for this passage may be to practice separately the two melodic lines: the octave writing as a main melodic line and the figurative accompaniment in demisemiquavers.

The pedal use suggested by the composer makes this fragment quite unique. The indication to maintain the damper pedal during each measure while the left hand plays an arpeggiated passage and the right hand a melodic line containing transition notes creates the impression of an apparent dissonance.

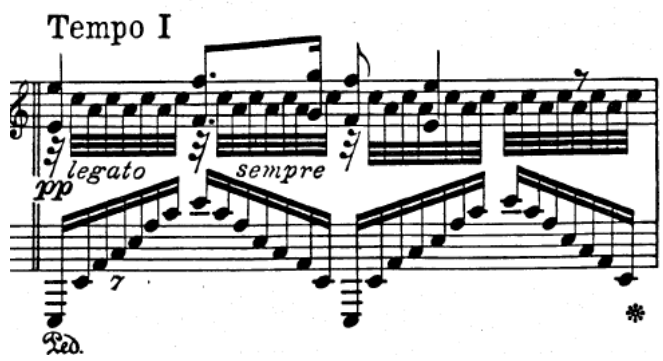

Fig. 8 E. Grieg, Piano Concerto in A minor, $1^{\text {st }}$ mvt, mm. 177

The cadence is very energetic and enthusiastic, and it offers the pianist the opportunity to demonstrate their technical as well as expressive skills.

The coda is brief, and begins with the orchestra playing the second musical idea in the main thematic group. It ends with a rhythmically heterogeneous adaptation of the theme in the introduction, played in crescendo by the piano. Thus, we can see the composer's wish to conclude the first movement of the Concerto in a circular motion, returning to the initial motif. The reiteration of those introductory chords is meant to bring back, by means of dynamics, balance and vivacity, a concert-like grandeur and brilliance, achieving formal unity of the first movement.

The Concerto's second movement is written in simple ternary form ABA and is exquisitely beautiful. The melody flows in waves that dissipate, succeed or run parallel to one another.

The first section (A) is performed exclusively by the orchestra, taking an atypical tonal path: D-flat major / E-flat minor. The composer's use of chordal 
writing draws the melodic idea closer to a chorale. The descant line unfolds on arpeggios and smaller intervals, and the ensuing mood is calm, pensive.

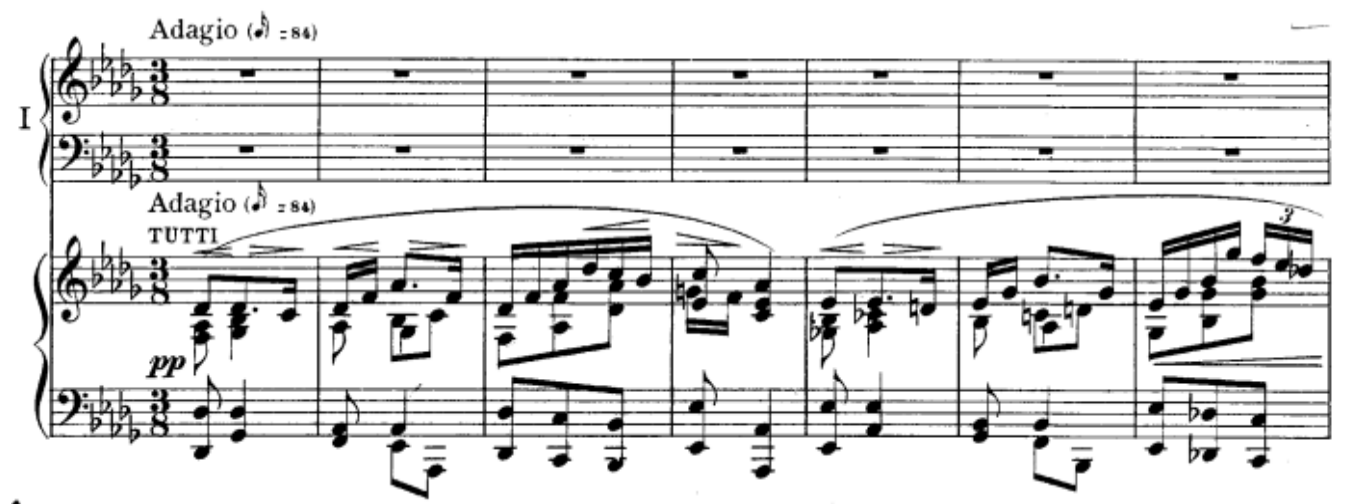

Fig. 9 E. Grieg, Piano Concerto in A minor, $2^{\text {nd }} \mathrm{mvt}, \mathrm{mm} .1-7$

In the middle part (B), the piano takes up the main role as the orchestra becomes the accompanist. The filigree melody with translucent sounds seems to draw from the second theme of the Concerto's first movement. The overall impression is that of a nocturne, the melodic line being particularly elevated and tranquil. The pianist requires great inner peace in order to be able to perform this part.
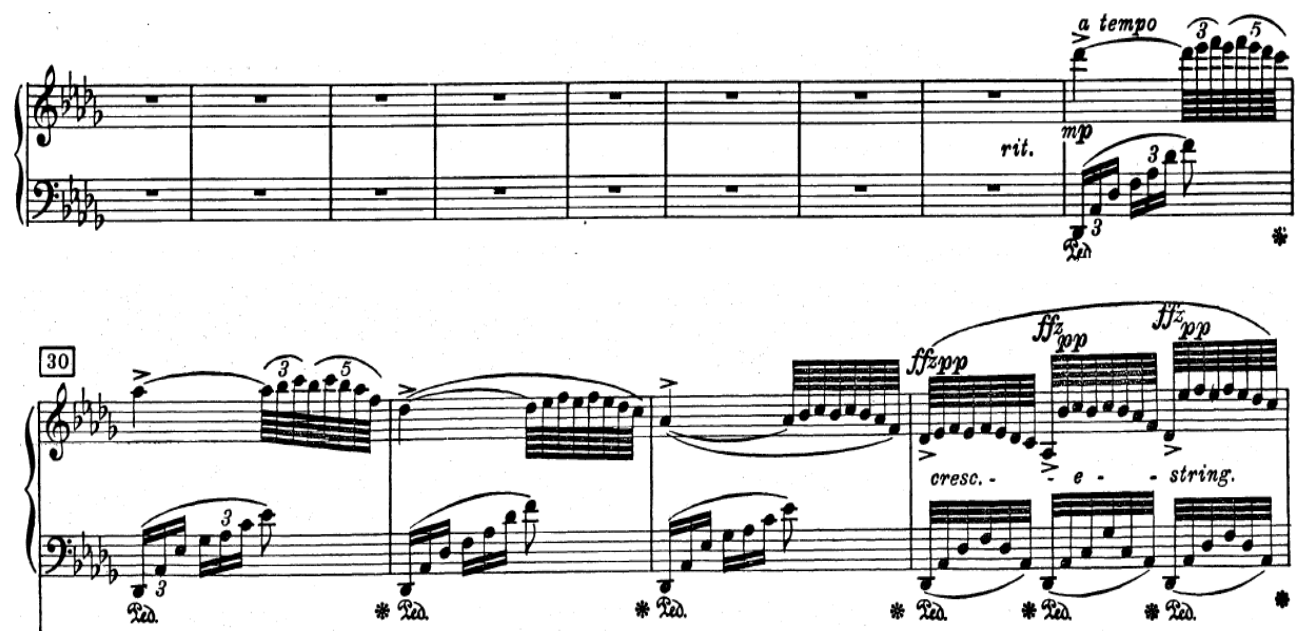

Fig. 10 E. Grieg, Piano Concerto in A minor, $2^{\text {nd }}$ mvt, mm. 21-33

The melancholy and meditative melody should not be hindered by the ornamentation suggestive of the ethos of the Norwegian fjords. Thus, the pianist should focus less on virtuosity and more on highlighting fluently the balance and musicality of this wonderful theme. Brief dramatic moments alternate here with the pervasive lyricism of the fragment. 
The initial theme occurs again at the end in a different instance: this time, the piano plays the main role and the orchestra supports it. Written in chords marked $f f$, the theme acquires eventually a completely new character, becoming grand and impressive, and exhibiting dramatic overtones.

Between the bars 64-73 there lies a truly beautiful passage which is constructed like a dialogue between the cello and the piano. The chords on the piano should convey warmth and lyricism, starting from a piano dolce and reaching $f f$ by an increasing dramatic tension.

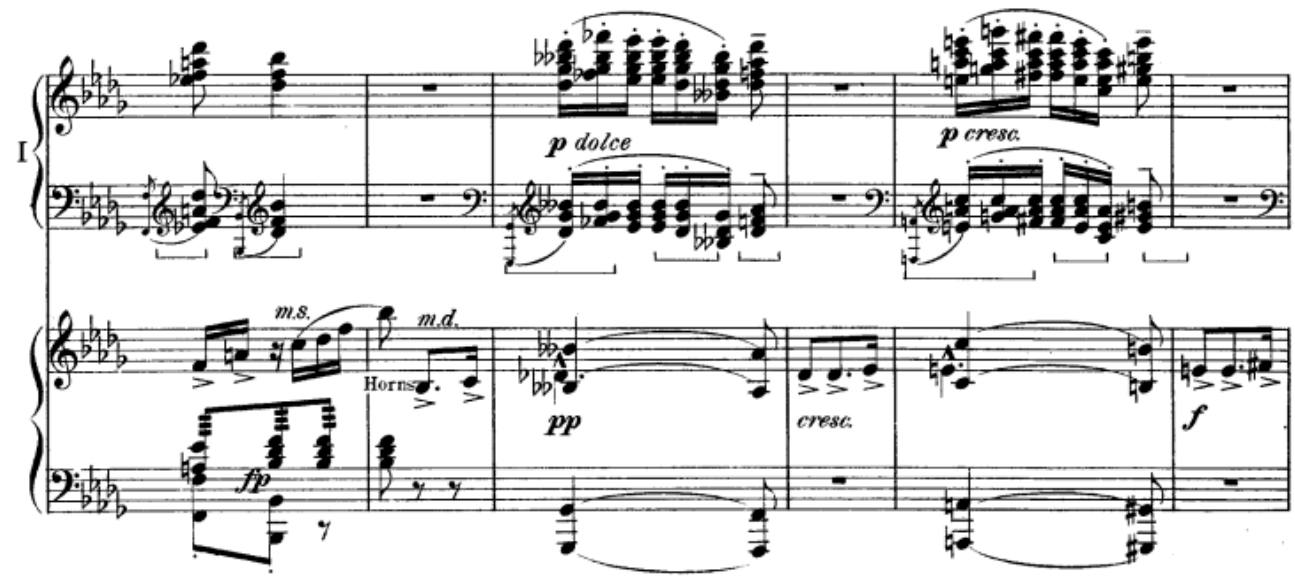

Fig. 11 E. Grieg, Piano Concerto in A minor, $2^{\text {nd }} \mathrm{mvt}, \mathrm{mm} .62-67$

In the measures 75 and 76 , the sixths at both hands should be highlighted individually, as the composer indicates that each must be emphasized and played tenuto.

The last six measures represent the conclusion of the second movement. In the bars 79 and 80, the two planes of the musical discourse follow a chromatic path in opposite directions, creating a duet that should be highlighted by emphasizing the soprano and the bass.

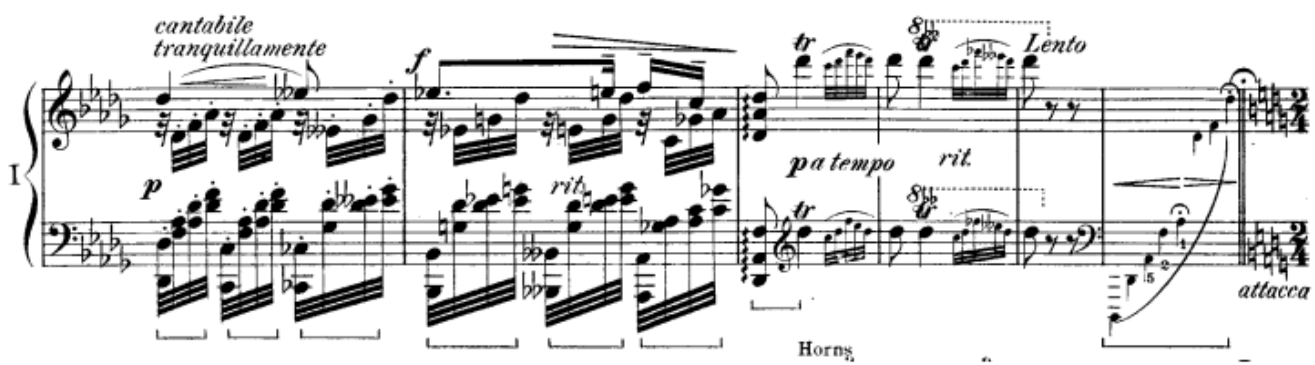

Fig. 12 E. Grieg, Piano Concerto in A minor, $2^{\text {nd }}$ mvt, mm. 79-84 
The concluding measure is filled with inner tension and should emanate warmth. To this purpose, the composer's dynamic marks ought to be observed. The pianist should achieve an increase in dynamics until D1, followed by a diminuendo.

Although at times there is an inner disquiet that cannot be suppressed, this second movement begins and ends in complete peacefulness, in a feeling of enchantment.

The third movement, Allegro moderato molto e marcato, exudes the Norwegian traditional character. "The extreme energy of the Norwegian dance appears like a determined rejection of foreign influences." (Dolinescu, 1964, p. 55)

Grieg chose to forgo any intermission between the second and the third movements of the Concerto, as evidenced by the attacca indicated at the end of the second movement.

The orchestra's four-measure introduction in $p p$ is followed by a similarly long virtuosic passage played by the piano in $f f$. In the last measure, the pianist has to perform a set of very rapidly descending scales. The density of the musical material entails the issue of containing the semiquavers within a single binary measure. Given that this is quite difficult to achieve, a possible approach - which is outside the box, due to the fact that it literally alters the musical text - would be to perform this measure as a 4-beat. The orchestra and the conductor wait for the pianist as though they observe a fermata, and this strategy facilitates their simultaneous entrance in the section poco animato that displays the first theme.
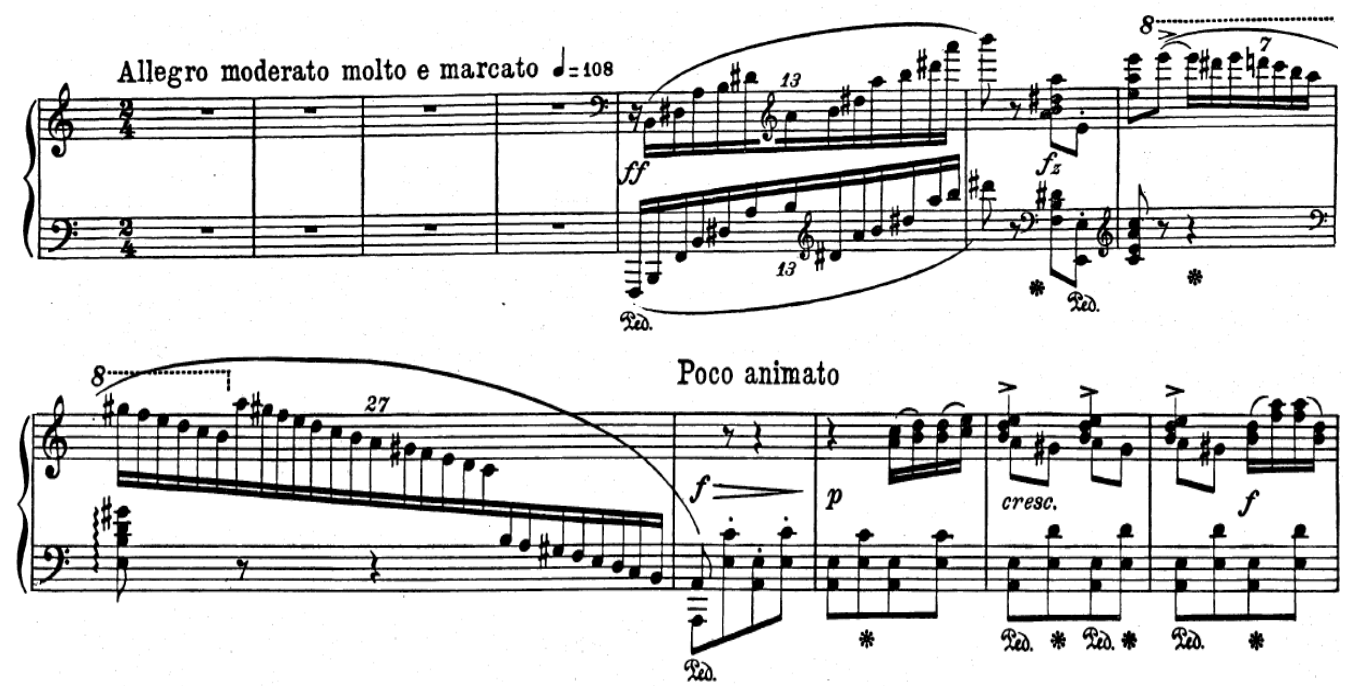

Fig. 13 E. Grieg, Piano Concerto in A minor, $3^{\text {rd }}$ mvt, mm. 1-12 
Conceived as a refrain of the bithematic rondo that concludes the Concerto, the melody opening this section is strong and energetic. At first it plays in the main tonality A minor, and then in its parallel key A major. "The Halling appears once again, but under a different form than that of the first movement; this one is a vigorous, almost wild, theme with a particularly dancelike rhythm." (Dolinescu, 1964, p. 55) The dance-like character should be rendered by the piano by observing all the indications in the score. The fast transitions from soft to strong dynamics, rapid crescendos and decrescendos or, on the contrary, tumultuous accumulations of increasing tension that climaxes dynamically are all very relevant aspects.

I believe it is essential that the pianist pay great attention to dynamics, and absolutely necessary that they be able to finely control it by employing various ways of key attack. In fact, all this stems from the inner ability to understand the variety of moods and emotions generated by the musical discourse, as well as from the desire - and capability - to transform abstract musical ideas into an expressive acoustic reality. The variety of key attacks required by the composer and the accents (those on the strong beats and especially the ones on the weak beats) are meant to highlight the traditional character of the music. This statement may seem trivial, but starting from the premise that a pianist who has reached the necessary level to approach such a piece can distinguish technically between staccato, legato and portato, I believe that any pianist could put these requirements into practice so long as they are able to understand deeply the importance of affording respect to the musical text and they regard as an imperative the intention to convey to their audience the musical meaning conceived by the composer.

The second musical idea (the first couplet) is written in the key of the relative major and is based on the rhythmic motif employed in the initial theme.

The middle couplet is characterised by an extremely beautiful lyrical theme which the composer develops extensively, making it quite independent in the context of the conclusion. This section should be regarded as a complete whole, since it does not contain any previously-used musical material.

First played by the flute in $\mathrm{F}$ major and then taken up by the piano, this theme stands in strong contrast to the previous ones. The melody - which can be likened to the Romanian doina - is affectionate and peaceful, with the composer choosing a more sedate tempo, poco piu tranquillo. 


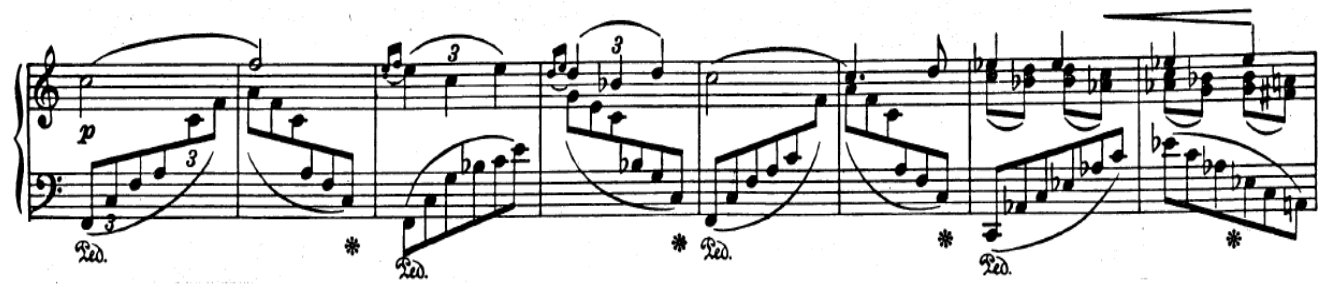

Fig. 14 E. Grieg, Piano Concerto in A minor, $3^{\text {rd }}$ mvt, mm. 163-170

From a performing perspective, the difficulty lies in personalizing distinctively the two musical planes: the melody in the upper plane, which has a warm sound and a tense phrase based on an apparent ad libitum; and the accompaniment, which has to discreetly provide the musical discourse with tranquillity and serenity. Moreover, in the descant the pianist should pay great attention to highlighting the main melodic line of the musical text. A possible solution to tackle this passage may be to practice the voices individually, which would make the musical discourse clearer and more easily performable in terms of phrasing. As a result of this exercise, we will notice a much-improved capability to "extract" the melodic line from the dense weave of the music. The mental strategy suitable to this approach is essential for its resolution. The pianist should aim at rendering the main melodic line in an equally legato and expressive manner, whether they are playing precisely what is written in the score or as they practice that voice individually. I personally believe that alternating practices are optimal - a purely technical, arid one, which is meant to clarify / resolve the performance issues, and an expressive one, where the deep emotional involvement has a profoundly musical purpose.

Bars 201-205 require very strong inner support of the musical phrase, otherwise the intrinsic warmth and dramatism are impossible to render.

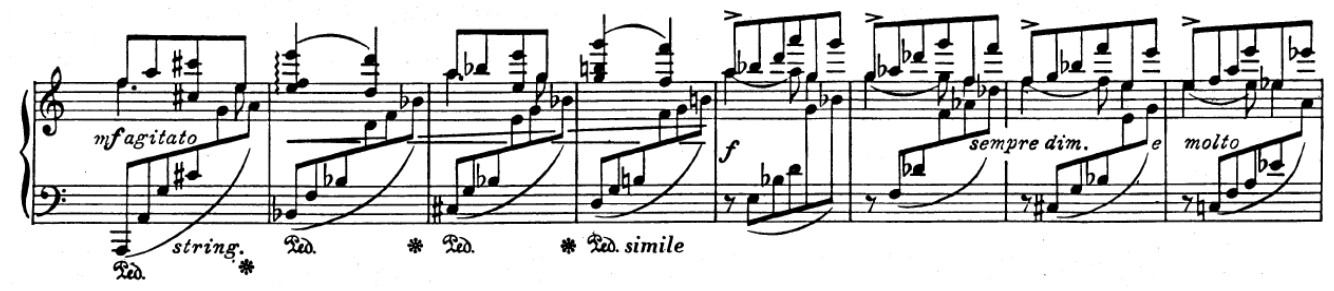

Fig. 15 E. Grieg, Piano Concerto in A minor, $3^{\text {rd }}$ mvt, mm. 201-208

The fragment captures an enormous accumulation of tension in quite a short time, after which the musical discourse settles gradually (perdendosi) until there is only a vague memory that ends in a series of arpeggiated chords in $p p p$. 
The intention to render as suggestively as possible the wide array of complex emotions teeming in the middle couplet compels the pianist to resort to their most intimate affective resources.

The refrain and the first couplet are played again, followed by a reprise of the former in its parallel key in triple metre. Thus, the binary Halling form changes here into a Springar, whose features are "a usually major tonality, having a fantastic and curious music exhibiting a lively, bouncy, restless rhythm that exudes an overwhelming love of live." (Dolinescu, 1964, p. 139)

This section can be viewed as a sort of piano cadence where the pianist is put in a position to prove their technical skills by having to play octaves, leaps and chords in a very fast tempo and with great ease. The composer chooses to increase the tempo, indicating it as quasi presto.

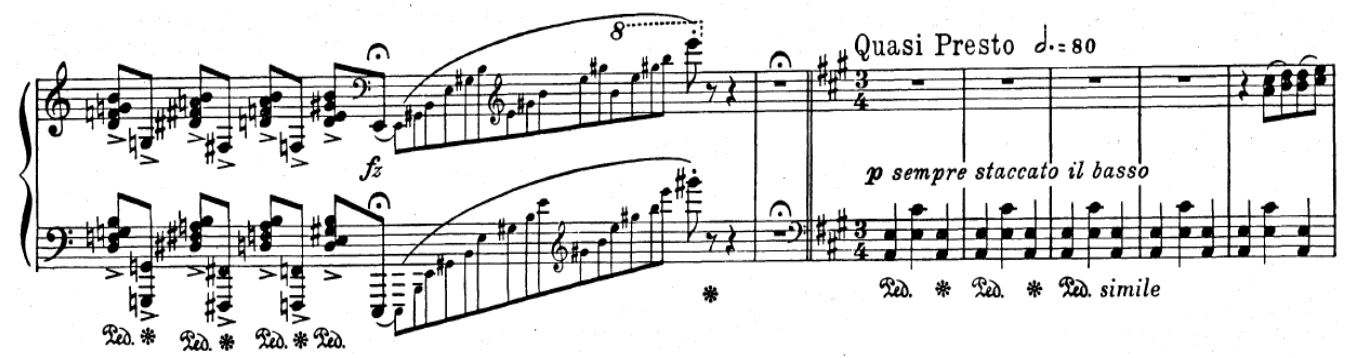

Fig. 16 E. Grieg, Piano Concerto in A minor, $3^{\text {rd }} \mathrm{mvt}$, mm. 252-258

To facilitate the transition from one tempo to another, we can choose to imagine that the tempo remains the same but the pianist has to mentally switch from duple to triple time. As concerns the dynamics, the theme climaxes in $f$ and $f f$.

Although the section opens in $p$, the dynamic and agogic intensity gradually increases (sempre piu $f$, sempre piu stretto), building up more and more tension that will climax in the coda.

It is quite difficult to observe the indication piu stretto, because the tempo established by Grieg at the beginning of this section is extremely fast and hard to surpass. But if we initially select a tempo just a little slower, then we would be able to play that stretto intended by the composer, which will have great artistic effect.

The concluding section of the Concerto, the Coda, sees the orchestra replay the lyrical theme of the middle couplet, but this time as andante maestoso in $f f$, exhibiting a different character, grand and heroic. At the same time, the piano plays in fff a series of arpeggios meant to enhance the triumphant and festive character of the Concerto's conclusion; this requires the pianist to produce a brilliant sound and to collaborate perfectly with the conductor. 


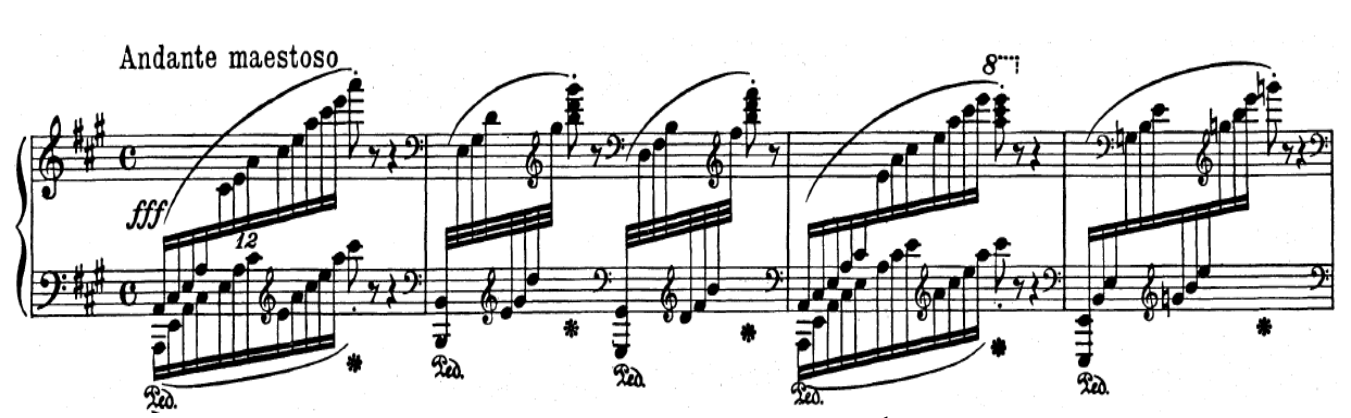

Fig. 17 E. Grieg, Piano Concerto in A minor, $3^{\text {rd }}$ mvt, mm. 423-426

To this purpose, the composer's use of a contrasting, lyrical theme, which is given a whole new colour, creates a very powerful impression on the audience.

Grieg's Piano Concerto in A minor, op. 16 allows each pianist to display their musicality as well as technical skills. The Concerto is very well-liked by audiences and pianists alike, due to its Norwegian air and the beauty, simplicity and accessibility of its melodic lines that make one's heart vibrate.

\section{Conclusions}

My choice to research this subject came naturally as a result of my experience as a pianist and piano teacher. I deemed it appropriate and necessary to write an article on some of the technical and performative issues in Edvard Grieg's Piano Concerto in A minor, op. 16, because I view it as an interesting topic yet not discussed enough from the pianist's perspective. Although they are personal and implicitly debatable, my opinions on the Concerto may prove, I believe, quite useful to the young pianists who wish to approach this repertoire.

I confess I have often found myself in a position to want to research various works for piano and, even though we are living in the age of the internet, I have come to learn that there is not enough - or even none at all documentation on how to perform such world-famous musical works (Grieg's Piano Concerto in A minor being an example in this respect).

I am aware that, at present, the field of musical research is mainly represented by musicology investigations which, in turn, focus on analysing modern and contemporary opuses in an attempt to avoid redundant research. Nevertheless, I firmly believe that the issue of piano stylistics and piano performance can be considered, if not inexhaustible, at least in a continuous development.

These are the reasons behind my decision to approach the subject. Starting from general assertions on certain elements typical of Grieg's compositional style and continuing with observations on form, melody, rhythm 
and harmony, I have attempted to present my own version of how this Concerto can be performed.

Besides the many auditions of great performances and the extensive bibliographical documentation on the composer's life and oeuvre, the providing of technical and performative solutions can be a starting point - one extremely beneficial for the pianists' research and instrumental in their artistic and professional evolution.

I believe this Concerto should be part of every concert pianist's repertoire, given that it is very appealing to the audience, it possesses an unexpected thematic richness and it is a work where the simple yet resourceful melodic lines blend beautifully with the brilliance of virtuosic passages.

\section{References}

Corredor, J.M. (1964). De vorbă cu Pablo Casals [Talking to Pablo Casals]. București: Editura Muzicală a Uniunii Compozitorilor din R.P.R.

Dale, K. (1943). Edvard Grieg's Pianoforte Music. Music \& Letters, 24, № 4, 193207. Retrieved from: htpps://www.jstor.org/stable/727023

Dolinescu, E. (1964). Grieg. București: Editura Muzicală a Uniunii Compozitorilor din R.P.R.

Grieg, E. Piano Concerto in A minor, op. 16. Frankfurt, New York, London: C. F. Peters. Retrieved from: https://imslp.org/

Grieg, E. Piano Concerto in A minor, op. 16 (piano reduction). www.free-scores.com Iliuţ, V. (1996). O carte a stilurilor muzicale [A Book of Musical Styles], $2^{\text {nd }}$ vol. Bucuresti: Editura Academiei de Muzică.

Kijas, A. E. (2013). 'A Suitable Soloist For My Piano Concerto': Teresa Carreño as a Promoter of Edvard Grieg's Music. Notes, 70, 1, 37-58. Retrieved from: htpps://www.jstor.org/stable/43672696 